\title{
Управление маркетинговой деятельностью российских вузов и его адаптация к изменяющимся рыночным условиям в экономике России и на глобальных рынках
}

\author{
Шумакова И.А. \\ Белгородский национальный исследовательский университет, \\ Россия, 308015, г. Белгород, ул. Победы, 85 \\ E-mail: shumakova@bsu.edu.ru
}

\begin{abstract}
Аннотация. Актуальность темы авторского исследования связана с необходимостью последовательного и системного достижения национальных целей развития Российской Федерации на период 2020-2030 гг. и основополагающим значением эволюции сферы высшего образования и образовательных рынков в контексте необходимости прорывной социально-экономической динамики, обоснованной, прежде всего, созданием комплекса возможностей, связанных с самореализацией и поступательным развитием личности. Самостоятельным направлением развития маркетинговой стратегии образовательных организаций высшей школы в настоящее время является выход на национальные и международные рынки с перспективой активизации экспорта образовательных услуг, привлечения международных образовательных потоков и эффективного позиционирования в глобальном научно-образовательном пространстве. Достижение конкретных результатов в указанной области, связанное с необходимостью прорывного скачка в качестве образовательных процессов, созданием национальной системы профессиональной ориентации и самоопределения перспективной молодежи, качественным ростом научно-исследовательской деятельности в сфере высшего образования, восстановлением и последовательной целевой реализацией воспитательно-образовательной функции и создания позитивного ценностно-нормативного ядра личности обучаемых, а также вовлечением их в социальную и культурную активность, требует от современных вузов как перспективных центров «экономики знаний» качественно нового уровня маркетинговых, социальных и экономических взаимодействий с ключевыми партнерами, ориентированного на устойчивое и эффективное функционирование и развитие.
\end{abstract}

Ключевые слова: маркетинговая деятельность, университет, маркетинговое управление, конкурентоспособность, управление организацией бенчмаркинг.

Для цитирования: Шумакова И.А. 2021. Управление маркетинговой деятельностью российских вузов и его адаптация к изменяющимся рыночным условиям в экономике России и на глобальных рынках. Экономика. Информатика, 48 (1): 72-81. DOI: 10.52575/2687-0932-2021-48-1-72-81.

\section{Management of marketing activities of Russian universities and its adaptation to changing market conditions in the economy Russia and global markets}

\author{
Shumakova I.A. \\ Belgorod State University, 85 Pobedy St, Belgorod, 308015, Russia \\ E-mail: shumakova@bsu.edu.ru
}

\begin{abstract}
The relevance of the author's research topic is related to the need for consistent and systematic achievement of the national development goals of the Russian Federation for the period 2020-2030. and the fundamental importance of the evolution of higher education and educational markets in the context of the need for breakthrough socio-economic dynamics, justified primarily by the creation of a complex of opportunities related to self-realization and progressive development of the individual. An independent direction in the development of the marketing strategy of higher education organizations is currently entering national and international markets with the prospect of increasing the export of educational services, attracting international educational flows and effective positioning in the global scientific and educational
\end{abstract}


space. Achievement of concrete results in this area, associated with the need for a breakthrough leap in the quality of educational processes, the creation of a national system of professional orientation and selfdetermination of promising young people, the qualitative growth of research activities in higher education, the restoration and consistent targeted implementation of the educational function and the creation of a positive value-normative core of the personality of students, as well as their involvement in social and cultural activities, it requires modern universities as the first centers of the "knowledge economy" to achieve a qualitatively new level of marketing, social and economic interaction with key partners, focused on sustainable and effective functioning and development.

Keywords: marketing activities, University, marketing management, competitiveness, organization management benchmarking.

For citation: Shumakova I.A. 2021. Management of marketing activities of Russian universities and its adaptation to changing market conditions in the economy Russia and global markets. Economics. Information technologies, 48 (1): 72-81 (in Russian). DOI: 10.52575/2687-0932-2021-48-1-72-81.

\section{Введение}

Достижение конкретных результатов в указанной области, связанное с необходимостью прорывного скачка в качестве образовательных процессов, созданием национальной системы профессиональной ориентации и самоопределения перспективной молодежи, качественным ростом научно-исследовательской деятельности в сфере высшего образования, восстановлением и последовательной целевой реализацией воспитательно-образовательной функции и создания позитивного ценностно-нормативного ядра личности обучаемых, а также вовлечением их в социальную и культурную активность, требует от современных вузов как перспективных центров «экономики знаний» качественно нового уровня маркетинговых, социальных и экономических взаимодействий с ключевыми партнерами, ориентированного на устойчивое и эффективное функционирование и развитие. Успех устойчивой работы на образовательном рынке для университета зависит от реализуемой маркетинговой стратегии, отправной точкой в которой выступает рынок труда, запросы на научные исследования и разработки, далее, имеющийся потенциал вуза.

\section{Материалы и методы исследования}

Существующая российская методология маркетинга образования представлена весьма интересным научным ландшафтом, отражающим попытки отдельных ученых, творческих коллективов и научных школ в части применения традиционного и инновационных маркетинговых подходов к деятельности вузов [Акименко, 2007; Вандрикова, 2017; Колесник, 2016; Пешкова, 2020; Пономарева, 2016; Умавов, 2012; Шевченко, 2016; 2017], которые занимались изучением маркетинговой среды и особенностями поведения потребителей образовательных услуг высшей школы.

\section{Основные результаты исследования}

Достижение конкретных результатов в указанной области, связанное с необходимостью прорывного скачка в качестве образовательных процессов, созданием национальной системы профессиональной ориентации и самоопределения перспективной молодежи, качественным ростом научно-исследовательской деятельности в сфере высшего образования, восстановлением и последовательной целевой реализацией воспитательно-образовательной функции и создания позитивного ценностно-нормативного ядра личности обучаемых, а также вовлечением их в социальную и культурную активность, требует от современных вузов как перспективных центров «экономики знаний» качественно нового уровня маркетинговых, социальных и экономических взаимодействий с ключевыми партнерами, ориентированного на устойчивое и эффективное функционирование и развитие.

Современные вузы также имеют значительный потенциал участия в реализации усилий в рамках инициатив «Комфортная и безопасная среда для жизни», «Достойный, эффек- 
тивный труд и успешное предпринимательство», «Цифровая трансформация» с перспективой формирования инновационно-ориентированных экосистем, обладающих стабильной маркетинговой позицией и способных обеспечить эффективную социально-экономическую интеграцию субъектов образовательных и смежных рынков.

Самостоятельным направлением развития маркетинговой стратегии образовательных организаций высшей школы в настоящее время является выход на национальные и международные рынки с перспективой активизации экспорта образовательных услуг, привлечения международных образовательных потоков и эффективного позиционирования в глобальном научно-образовательном пространстве.

Однако указанные перспективы требуют качественного роста эффективности маркетингового управления в части разработки и реализации перспективных форм и направлений организации маркетинговой деятельности вузов, призванных обеспечить высокое качество маркетинговой адаптации образовательных организаций к волатильности региональных, национального и международных рынков на основе прикладной реализации прогрессивных маркетинговых подходов и концепций, прежде всего холистической концепции, с учетом отраслевых особенностей и ограничений социально-этического характера.

Актуальность темы связана с необходимостью последовательного и системного достижения национальных целей развития Российской Федерации на период 2020-2030 гг. [О национальных целях...] и основополагающим значением эволюции сферы высшего образования и образовательных рынков в контексте необходимости прорывной социальноэкономической динамики, обоснованной, прежде всего, созданием комплекса возможностей, связанных с самореализацией и поступательным развитием личности.

Изучением маркетинговой функции образовательных организаций занимался ряд ученых [Бобрик, 2013; Ешмуратова, 2012; Земляк, Савченко, 2012; Иманкулова, 2011; Кузьмина, 2014; Леденева, 2009; Платошина, 2007; Попов, 2013; Хугаева, 2016].

Ретроспективный анализ управленческого подхода к организации маркетинговой деятельности организационных субъектов показал, что ведущие исследователи проблем маркетингового управления недостаточно четко разграничивают содержание и специфику маркетинговой функции в составе корпоративного управленческого инструментария и непосредственно маркетинг-менеджмент, причем следует признать слабо разработанной на данный момент саму концепцию «идеального маркетингового управления», в рамках которой возможно полное удовлетворение запросов и интересов всех субъектов современных маркетинговых систем.

Процессная организация маркетингового управления, отстаиваемая рядом авторов, требует уточнения в части состава, специфики, ресурсов и результатов реализации конкретных процессов, которые в значительной степени отличаются в различных видах экономической деятельности, особенно по фактору времени предоставления экономического блага и возможностей дальнейшего маркетингового взаимодействия на основе концепции потока потребительской ценности.

Подчеркнем и высоко отметим содержательность определения А.А. Барановского [Барановский, 2007], указывающего на существенные особенности маркетингового управления в образовании, состоящие в повышении потребительской ценности уникального торгового предложения образовательных услуг и продуктов на основе формирования и развития корпоративного «человеческого капитала» и модернизации состава и отдельных образовательных технологий и продуктов», ключевым показателем этой деятельности, по мысли автора, должен стать рост конкурентоспособности конкретного вуза.

Автором сформулированы следующие выводы относительно состава и значимости проблем разработки, реализации и оценки эффективности управления маркетингом на рынках товаров и услуг:

- современный уровень теоретического поиска в части проблем маркетингового управления ограничен поиском содержательных отличий между функциональной и интегрированной формой реализации маркетинговых воздействий, причем подавляющее большин- 
ство авторов отождествляют реализацию нескольких маркетинговых функций и маркетинговое управление, на наш взгляд, без должного методологического обоснования;

- нуждается в значительном пересмотре и модернизации методология организации маркетингового управления в части перехода от реализации отрывочных маркетинговых воздействий и интуитивной оценки их эффективности к системному и целенаправленному процессу создания и реализации маркетинговых и конкурентных преимуществ, обеспечивающих рост корпоративной стоимости и устойчивое и долгосрочное достижение целей функционирования предприятий и организаций в пределах маркетинговых систем;

- самостоятельным направлением научного поиска в части повышения эффективности управления маркетингом на рынках товаров и услуг является отраслевая и локальная специфика осуществления видов экономической деятельности и возможностей их маркетингового сопровождения, учитывающего стратегические детерминанты потребительского поведения в части выбора товара / услуги и поставщика, процесса покупки и послепродажных процессов, в том числе внутренних маркетинговых возможностей в случае длительного цикла операционного взаимодействия, а также предпосылок реализации резерва лояльности и долгосрочных взаимовыгодных отношений как значимого нематериального маркетингового актива.

Концепция маркетингового управления в настоящее время относится к числу недостаточно разработанных, но крайне востребованных со стороны теории, методологии и практики маркетинговых концепций, и характеризует качественно более высокий в сравнении с функциональной организацией маркетинга подход к пониманию, инициации и использованию фундаментальных рыночных взаимодействий с учетом особенностей специфики конкретных рыночных (маркетинговых) локаций.

Сущность маркетингового управления определена нами в контексте полного охвата потребительского поведения на всех его стадиях, в том числе на этапе послепродажных процессов и обратной конверсии, ориентированных на выход за пределы задачи по стохастическому привлечению платежеспособного спроса, характерного для реализации фрагментарных маркетинговых воздействий и централизованной маркетинговой функции, и переход к методологии формирования устойчивого и качественного клиентского потока за счет монетизации корпоративной системы нематериальных маркетинговых активов, к числу которых мы отнесли уровень удовлетворенности покупателей / потребителей, инструменты и методики адвокации бренда в потребительских потоках и сообществах, а также показатели сформированного единичного или потокового лояльного спроса.

В современных условиях маркетинговое управление современной организацией ориентировано прежде всего на конкурентоспособность и конкурентную устойчивость корпоративного субъекта в системе волатильных маркетинговых факторов макро- и микросреды, учитывает необходимость формирования ядра корпоративной конкурентоспособности и инициации системы нуклеарных и воспроизводственных маркетинговых процессов, способных обеспечить развитие долгосрочных регулярных взаимовыгодных отношений в системе маркетинга с учетом холистической социально-этичной маркетингово-корпоративной ориентации.

Авторский подход к развитию теории маркетингового управления, ориентированного на конкурентоспособность, включает в себя следующие элементы:

- сравнительную характеристику традиционной и современной моделей принятия и реализации потребительского решения в части особенностей и возможностей децентрализации и интеграции маркетинговой функции с перспективой перехода к полноформатному маркетинговому управлению;

- классификацию особенностей децентрализованной (фрагментарной), централизованной и интегрированной форм реализации маркетинговых функций в контексте эффективности маркетингового управления; 
- разграничение и содержательное описание направленности, эффективности и возможностей интеграции маркетинговых воздействий при реализации функционального и системно-управленческого подходов к организации маркетинговой деятельности; управления.

- разработку актуальной корпоративной модели стратегического маркетингового

Проблемы управления маркетинговой деятельностью в российской высшей школе связаны прежде всего с наличием ряда существенных особенностей формирования и развития маркетинговой среды и факторов поведения потребителей образовательных услуг высшей школы:

- усиление административного регулирования сферы предложения образовательных услуг и продуктов в части институционального состава (с акцентом на государственные и муниципальные вузы) и качества предоставляемых услуг в части их соответствия федеральным образовательным стандартам;

- значительный уровень иррациональности факторов потребительского выбора образовательного продукта / услуги и вуза-поставщика на фоне значимости семейного фактора (одобрения родителями - покупателями продукта / услуги);

- недостаточный уровень внедрения традиционных инструментов управления маркетингом, прежде всего маркетинговых информационных систем, адаптированных к специфике образовательной деятельности среднего и высшего профессионального уровня.

Необходимо подчеркнуть фрагментарность современных исследовательских инициатив в части поиска и экономически целесообразной реализации конкретных маркетинговых резервов, заложенных в концепции маркетингового управления, ориентированного на получение системы долгосрочных комплексных эффектов маркетингового, операционного, социально-экономического плана. Объединяющими имеющие место подходы моментами являются именование скорости маркетинговых изменений и конкурентоспособности вуза как соответственно основной причины и стратегического результата маркетингового управления, а также понимание возможностей внутренней фокусировки образовательной организации на эффективном взаимодействии и дополнительных маркетинговых воздействиях на потребителей образовательных услуг и продуктов, находящихся в ходе получения соответствующего экономического блага. Возвратный (ремаркетинговый) поток лояльных клиентов и усиление их роли и значимости в формировании операционных итогов работы вуза, предшествующих началу учебного года (набор контингента обучающихся) не нашел должного рассмотрения и обоснования в рассмотренных трудах российских исследователей.

Подчеркивая перспективность применения отдельных цифровых возможностей и технологий в процессах маркетингового и операционного взаимодействия вуза с субъектами его системы маркетинга, отметим, что непосредственно цифровой формат образовательного маркетинга всего лишь открывает новые технологические возможности, способствующие повышению эффективности функционального взаимодействия и реализации определенных маркетинговых резервов.

Цифровой маркетинг в сфере образования может и должен быть ориентирован на поддержку конкретного формата функциональной реализации маркетингового инструментария управления (децентрализованный фрагментарный маркетинг, централизованная маркетинговая функция, маркетинговое управление) с соответствующей организационной, нормативной и бюджетной поддержкой, а также преимущественно процессной и непрерывной формой реализации с вовлечением всех целевых аудиторий и стейкхолдеров, обладающих потенциалом роста эффективности деятельности вузов и их конкурентоспособности на существующих и перспективных образовательных рынках.

В исследовании выявлен недостаточный, на наш взгляд, уровень научного понимания и теоретико-методического обоснования современных концепций и представлений о необходимости, содержании и конкретных направлениях управления маркетинговой деятельностью современных российских вузов, ориентированных на конкурентоспособность. Аксиоматическое утверждение об обострении конкурентной борьбы на локальных или региональных рынках об- 
разовательных услуг, характерное для большинства отечественных авторов, не обосновано конкретными фактами потребительского выбора и поведения, а связано, на наш взгляд, прежде всего, с негативными демографическими тенденциями - т. е. факторами, качественно отличающимися от детерминантов конкуренции.

В настоящее время развитие образовательных рынков регионального и национального масштаба в Российской Федерации характеризуется усилением государственного давления и ужесточением администрирования предложения образовательных услуг и продуктов в части институционального состава (с акцентом на государственные и муниципальные вузы) и качества предоставляемых услуг в части их соответствия федеральным образовательным стандартам. При этом особенностями современного этапа внедрения концепции маркетингового управления являются значительный уровень иррациональности факторов потребительского выбора образовательного продукта/услуги и вуза-поставщика на фоне значимости семейного фактора (одобрения родителями - покупателями продукта / услуги) и фрагментарность внедрения традиционных инструментов управления маркетингом. При этом рыночная конъюнктура определяется скоростью маркетинговых изменений и конкурентоспособностью вуза, и является основным фактором результативности маркетингового управления.

Отраслевой особенностью стратегической конкурентоспособности вуза является отсутствие жесткой детерминированности результатов обучения и невозможность линейной связи, например, бренда вуза и уровня оплаты труда выпускников на определенных этапах профессиональной траектории, в силу отсутствия (недостаточного масштаба) опыта трудовой деятельности и первичной профессиональной ориентации в конкретном виде экономической активности, недостаточной эффективности профессиональной ориентации представителей целевой клиентской группы потенциальных потребителей образовательных услуг и продуктов в период их активизации и конверсии в состояние клиентского потока «Абитуриенты», отсутствия заинтересованности вуза в заключительном маркетинговом контроле реального качества и конкурентоспособности образовательной услуги / продукта в течение 3, 5 и 10-летних интервалов профессиональной деятельности выпускников (в силу затратности подобного рода исследовательских мероприятий и отсутствия прямого экономического эффекта от их осуществления).

Конкурентоспособность современного вуза относится к числу категорий образовательного рынка и имеет теоретическое и практическое значение в маркетинговой ориентации отечественных образовательных организаций на современные российские вузы, на формирование локальных / региональных, а также межрегиональных / национальных и международных потоков абитуриентов и обучаемых, позволяет образовательной организации участвовать в национальных и международном маркетингово-конкурентном процессе. Прикладная постановка и реализация прикладных целей и задач роста конкурентоспособности в составе перспективных маркетинговых стратегий требует существенной модернизации теоретического и организационно-экономического обеспечения, учитывающего необходимость повышения конкурентоспособности вуза в условиях ярко выраженной специфики маркетинговых взаимодействий, сопровождающих организацию, течение и финализацию основного образовательного процесса и возможностей, его сопровождающих.

Современные российские вузы свободны в формировании не только локальных / региональных, но и межрегиональных / национальных и международных потоков абитуриентов и обучаемых, способны выступать субъектами конкуренции на национальном и глобальных рынках, привлекать на обучение и использовать маркетинговый потенциал клиентских групп и потоков из-за традиционных региональных, а в случае городов - федеральных центров национальных границ рыночных локаций. Однако постановка и реализация прикладных целей и задач роста конкурентоспособности в составе перспективных маркетинговых стратегий требует конкретного и точного определения используемых терминов и категорий, применения релевантных оценочных показателей, характеризующих динамику роста конкурентоспособности и реальную эффективность маркетинговых управленческих воздействий и активности образовательных организаций. 
Приращение научного знания, представленное в авторском подходе к организации и повышению эффективности управления маркетинговой деятельностью, ориентированного на перманентный рост конкурентоспособности образовательных организаций, состоит в:

- развернутой характеристике и выявлении отраслевой и маркетинговой специфики конкуренции как формы, ориентира и фактора эффективности маркетингового управления современной образовательной организацией;

- раскрытии особенностей конкурентоспособности вуза как социальноэкономического института и центрального субъекта маркетинговых систем;

- обосновании репрезентативной и релевантной системы показателей и методов оценки конкурентоспособности вуза с позиций маркетингового управления;

- определении перспективных направлений и методов маркетингового управления конкурентоспособностью образовательной организации на различных уровнях организации маркетинговых воздействий.

На наш взгляд, в маркетинговом управлении современным вузом должны быть четко структурированы и упорядочены ключевые направления повышения конкурентоспособности, соотнесенные с имеющимися стратегическими, операционными и тактическими маркетинговым возможностям. Такой подход позволяет обеспечить интеграцию маркетинговых усилий по росту конкурентоспособности выпускников и использованию ресурса взаимодействий с ними в маркетинговой стратегии образовательного учреждения, росту конкурентоспособности на целевом рынке в виде перераспределения клиентского потока абитуриентов и занятия доли рынка, необходимой для ведения образовательной деятельности, а также росту конкурентоспособности вузов как реальных центров «экономики знаний», способных к генерации и коммерциализации инноваций как перспективного направления постиндустриального экономического развития.

Исследование научно-исследовательского ландшафта маркетингового управления в образовательной деятельности современных российских вузов показало, что имеет место недостаточность существующей системы статистического наблюдения в сфере образования, характеризующейся полным охватом деятельности образовательных организаций, но не дающей представления о закономерностях и границах образовательных рынков различных масштабов и специфики. В то же время необходимо положительно оценить концентрированный характер полевых исследовательских инициатив ряда отечественных авторов, отвечающий целям и задачам конкретных диссертационных исследований, но не позволяющий получить комплексную маркетинговую характеристику целевых рынков, в том числе в разрезе клиентских групп и потоков. Кроме того, отметим явно недостаточное количество системных разработок методологии маркетингового управления в привязке к специфике потребительского поведения и мотивам потребительского выбора клиентских групп и потоков, обусловленных спецификой образовательной деятельности в целом и ее существенных маркетинговых аспектов (операционный цикл, лояльность, зависимость от бюджетного финансирования, деградация организационного ценоза и т. д.) в частности.

Развитие научных представлений в части повышения функциональности маркетингового управления образовательными организациями высшей школы, учитывающего специфику образовательного вида деятельности и наличие, и структуру клиентских групп и потоков осуществлено нами в следующей логической последовательности:

- классификация методов планирования, организации, мотивации и контроля в структуре стратегических, операционных и тактических маркетинговых взаимодействий, и воздействий;

- классификация форм организации маркетингового управления в образовательной организации;

- особенности формирования и эволюции организационных структур маркетинга в образовательной организации в соответствии с масштабами реализации концепции маркетингового управления; 
- система операционных и маркетинговых результатов и эффектов деятельности организационных структур маркетинга в образовательной организации в соответствии с масштабами реализации концепции маркетингового управления;

- система стратегических результатов деятельности организационных структур маркетинга в образовательной организации в соответствии с масштабами реализации концепции маркетингового управления.

Итогом прикладной реализации авторского подхода должен стать системный рост конкурентоспособности и конкурентной устойчивости образовательных организаций на всех типах образовательных рынков, обоснованный численностью и качеством личности и профессиональной компетентности выпускников, которые, в случае позитивного потребительского опыта получения образовательных продуктов и услуг, способны к формированию ремаркетинговых клиентских запросов и потоков, эффективной адвокации бренда в цифровых каналах коммуникаций и референтных группах, формированию и развитию целевых потребительских сообществ, регулярным экономическим и неэкономическим взаимодействиям с alma mater, прямо определяющей траекторию личного и профессионального развития на протяжении всей жизни конкретного человека.

\section{Заключение}

Проведенное исследование позволило получить следующие результаты. Национальный рынок услуг и продуктов высшего образования относится к числу весьма волатильных маркетинговых систем, характеризуемых противоречивыми особенностями и тенденциями функционирования и развития на фоне стратегического значения сферы образования в перспективном социально-экономическом развитии Российской Федерации. Рассматриваемый рынок трудно считать полноценной маркетинговой системой, функционирующей в соответствии с рыночными законами и закономерностями. Масштабы поступления средств в конкретные образовательные организации в значительной мере зависят от форм и методов бюджетного финансирования всех реализуемых видов деятельности (образовательная, научноисследовательская, прочая).

Соответственно целесообразность массированного внедрения и применения инструментария маркетингового управления может создать дополнительные конкурентные преимущества, но не является в настоящее время единственным фактором роста образовательной конкурентоспособности, хотя и позволяет мобилизовать и реализовать стратегические долговременные резервы роста устойчивости функционирования и развития российских вузов.

\section{Список источников}

1. О национальных целях развития Российской Федерации на период до 2030 года. Указ Президента РФ от 21.07.2020 г. URL: http://kremlin.ru/events/president/news/63728_(дата обращения: 18 декабря 2020).

\section{Список литературы}

1. Акименко В.А. 2007. Аффилиарный маркетинг в рыночной политике государственных и негосударственных учреждений высшего профессионального образования. Автореф. дис. канд. экон. наук. Сочи, НОЦ российской академии образования, 19.

2. Барановский А.И. 2007. Управление маркетингом непрерывного многоуровневого образования. Омск, ОГПУ, 218.

3. Бобрик А.В. 2013. Система менеджмента качества и маркетинг учреждений высшего профессионального образования. Чрезвычайные ситуации: образование и наука, 8 (1): 77-82.

4. Вандрикова О.В. 2017. Маркетинг образовательных услуг в системе высшего образования. Вестник Академии знаний, 4: 65-70.

5. Ешмуратова А.Ф. 2012. Маркетинг в системе высшего образования как необходимый предмет. Современные научные исследования, 4: 22.

6. Земляк С. В., Савченко Ю. Ю. 2012. Маркетинг услуг высшего профессионального образования: компетентностная модель продукта. Современные проблемы науки и образования, 4: 202. 
7. Иманкулова Э.Т. 2011. Маркетинг образовательных услуг в системе менеджмента образования. Экономика, 10: 128-132.

8. Колесник Е.А. 2016. Маркетинг высшего образования: тенденции развития. Здоровье и образование в XXI веке, 18 (2): 749-752.

9. Кузьмина Е.Е. 2014. Маркетинг образовательных услуг. М., Юрайт, 330.

10. Леденева И.Н. 2009. Маркетинг в системе среднего профессионального образования. Вестник Саратовского государственного технического университета, 1: 214-223.

11. Пешкова И.Г. 2020. Маркетинговые коммуникации в современных образовательных организациях. Автореф. дис. ... канд. экон. наук. Ростов-на-Дону, РИНХ, 30.

12. Платошина Г.Г. 2007. Стратегический маркетинг высшего образования. Экономика образования, 4: 14-20.

13. Пономарева Е.А., Тлимахова Ф.А. 2016. Маркетинг в сфере образования. Сборники конференций НИЦ Социосфера, 61: 66-69.

14. Попов Г.Ю. 2013. Маркетинг отношений в учреждениях высшего профессионального образования. Автореф. дис. ... канд. экон. наук. М., РЭУ им. ГВ. Плеханова, 26.

15. Умавов Ю.Д. 2012. Маркетинг высшего образования: новые тенденции и перспективы. Вопросы структуризации экономики, 2: 41-44.

16. Хугаева М.В. 2016. Маркетинг в сфере высшего образования: особенности и перспективы развития. Образование и наука в современных условиях, 2-2: 207-209.

17. Шевченко Д.А. 2017. Маркетинг в сфере образования. Статья 2. Маркетинговая среда образовательной организации. Практический маркетинг, 1: 3-11.

18. Шевченко Д.А. 2016. Маркетинг в сфере образования: История становления и формирования рынка системы высшего образования в России. Психология и педагогика служебной деятельности, 4: 15-24.

\section{References}

1. Akimenko V. A. 2007. Affiliate marketing in the market policy of state and non-state institutions of higher professional education. Author of the dissertation of the Candidate of Economic Sciences. Sochi, REC of the Russian Academy of Education, 19.

2. Baranovsky A. I. 2007. Marketing management of continuous multi-level education. Omsk, OGPU, 218.

3. Bobrik A.V. 2013. Quality management system and marketing of institutions of higher professional education. Emergency situations: education and science, 8 (1): 77-82.

4. Vandrikova O. V. 2017. Marketing of educational services in the system of higher education. Bulletin of the Academy of Knowledge, 4: 65-70.

5. Eshmuratova A. F. 2012. Marketing in the system of higher education as a necessary subject. Modern scientific research, 4: 22.

6. Zemlyak S. V., Savchenko Yu. Y. 2012. Marketing of higher professional education services: a competency-based product model. Contemporary problems of science and education, 4: 202.

7. Imankulova E. T. 2011. Marketing of educational services in the system of education management. Economy, 10: 128-132.

8. Kolesnik E. A. 2016. Marketing of higher education: development trends. Health and education in the XXI century, 18 (2): 749-752.

9. Kuzmina E. E. 2014. Marketing of educational services. Moscow, Yurayt, 330.

10. Ledeneva I. N. 2009. Marketing in the system of secondary vocational education. Bulletin of the Saratov State Technical University, 1: 214-223.

11. Peshkova I. G. 2020. Marketing communications in modern educational organizations. Autoref. dis. ... candidate of Economic Sciences. Rostov-on-Don, RINH, 16.

12. Platoshina G. G. 2007. Strategic marketing of higher education. Economics of education, 4: 14-20. 61: 66-69.

13. Ponomarev E. A., Tlimakhov F. A. 2016. Marketing in education. Collection of conferences,

14. Popov G. Yu. 2013. Marketing of relations in institutions of higher professional education. Autoref. dis. ... Candidate of Economic Sciences, Moscow, Plekhanov Russian University of Economics, 26.

15. Umavov Yu. D. 2012. Marketing of higher education: new trends and prospects. Issues of structuring the economy, 2: 41-44.

16. Khugaeva M. V. 2016. Marketing in the sphere of higher education: features and prospects of development. Education and science in modern conditions, 2-2: 207-209. 
17. Shevchenko D. A. 2017. Marketing in the field of education. Article 2. Marketing environment of an educational organization. Practical marketing, 1: 3-11.

18. Shevchenko D. A. 2016. Marketing in the field of education: The history of the formation and formation of the market of the higher education system in Russia. Psychology and pedagogy of official activity, 4: 15-24.

\section{ИНФОРМАЦИЯ ОБ АВТОРЕ}

Шумакова Ирина Алексеевна, кандидат педагогических наук, доцент, доцент кафедры педагогики, директор департамента подготовки и аттестации научно-педагогических кадров Белгородского государственного национального исследовательского университета, г. Белгород, Россия

\section{INFORMATION ABOUT THE AUTHOR}

Irina A. Shumakova, Candidate of Pedagogical Sciences, Associate Professor, Associate Professor of the Department of Pedagogy, Director of the Department of Training and Certification of Scientific and Pedagogical Personnel Belgorod National Research University, Belgorod, Russia 